\title{
Split-Step Timing of Professional and Junior Tennis Players
}

\author{
by \\ Ales Filipcic ${ }^{1}$ Bojan Leskosek ${ }^{1}$, Tjasa Filipcic ${ }^{2}$
}

\begin{abstract}
The purpose of the study was to determine the timing of a split-step in three categories of tennis players in four groups of strokes. Subjects were divided into three groups: male and female junior, and male professional tennis players. During two tournaments, all matches were recorded with two fixed video cameras. For every stroke, the timing of the split-step between the opponent's impact point when hitting the ball and the player's split-step was measured. A twoway analysis of variance (ANOVA) was used to determine the differences between groups of strokes, players and the interaction Player $x$ Stroke Group. A Tukey post-hoc test was employed to determine specific differences. The results revealed differences between players in detecting the opponent's movement, stroke and ball flight, which were reflected in different split-step timings. Each tennis player has his/her own timing mechanism which they adapt to various game situations. Response times differ significantly depending on the game situation. On average, they are the lowest in the serve, and then gradually rise from the return of the serve to baseline game, reaching the highest values in specific game situations. Players react faster in the first serve than in the second one and in the return of the serve, the response times are lower after the return of the second serve.
\end{abstract}

Key words: tennis, movement, game situations.

\section{Introduction}

Tennis players have to perceive and interpret information quickly and effectively, thereby providing sufficient time to plan, initiate and execute a successful shot (Filipcic et al., 2009a). Through specifically oriented tennis practices, tennis players also develop perception skills and anticipation, defined as dynamic interactions between a number of perceptualcognitive skills (Williams et al., 2010). The ability to anticipate opponents' actions is crucial for performance in many sports, particularly where the uncertainty and spatiotemporal constraints on performance are significant (Filipcic et al., 2009a). Skilled tennis players are able to anticipate future events quickly and accurately (Hurnik et al., 2008), before performing a shot they pick up information from opponent's postural orientation (Martínez-
Gallego et al., 2013). They employ more effective and efficient visual search behaviors (Brody, 2006; Terroba et al., 2013; Triolet et al., 2013), are more attuned to relative motion information typically presented in the form of point-light images (Verlinden et al., 2004). In addition, they possess greater knowledge of situational probabilities or expectational information (Katic et al., 2011; O'Donoghue, 2006). Djurovic et al. (2009) found some differences between serve-return shots concerning the time of the occurrence of lateral racquet displacement, the amplitude of the racquet movement and the average latency time.

High-level tennis forces players to deal with very high time and space constraints. On the return of the serve, for example, when the serve is hit at $200 \mathrm{kph}$, the time available for action is

1 - University of Ljubljana, Faculty of Sport, Ljubljana, Slovenia.

2 - University of Ljubljana, Faculty of Education, Ljubljana, Slovenia. 
approximately $500 \mathrm{~ms}$ (O'Donoghue and Liddle, 1998). Aviles et al. (2002) reported that high-level tennis players returning the serve always performed a split-step (preparatory motion) before executing the return. In this situation, it is clear that the player's reaction time must be reduced to a minimum and that the dynamism of the response must be maximal. Cross and Pollard (2011) found that high-level tennis players performing a simulated split-step had shorter reaction and movement times than beginners, while males were quicker in movement times than females.

In tennis, players use a split-step before executing a movement in order to improve the efficiency of that movement (Elliott et al., 2003). A split-step is a small vertical jump or hop commonly used as a preparatory motion for a lateral step when receiving the ball (Torres-Luque et al., 2011). The split-step, an integral part of preparing for a volley, return of the serve or groundstroke, places the quadriceps muscle (extensor at the knee joint) into a stretch, permitting the storage and subsequent release of energy to enhance quick movement in advance of the subsequent stroke (Bernardi et al., 1998). In a simulated tennis response situation, Smekal et al. (2001) examined the benefit of a split-step. Highlevel tennis players performing a split-step that benefitted from the stretch-shortening type of muscle action used different ankle joint movement strategies and were able to start the movement faster.

Video motion tracking has been used in previous movement analysis studies in different sports such as squash (Eubank and Messenger, 2000; Hughes and Franks, 1994; James and Bradley, 2004; Vuckovic et al., 2003) basketball (Barris, 2008), handball (Pers et al., 2002), soccer (Barros et al., 2006), volleyball (Mauthner et al., 2007) and tennis (Carboch et al., 2014; Carvalho et al., 2013; Martínez-Gallego et al., 2013; Triolet et al., 2013).

Only a few studies have involved an analysis of split-step timing. We used video analysis of competitive matches and measured players' responses to opponents' shots when performing a serve and return of the serve, baseline shots and other shots (forehand and backhand slice, drop shot, drive volley, volley, overhead smash). The first aim of the present study was to identify the timing of a split-step in four groups of shots; the second aim was to determine the timing of a split-step in three categories of tennis players (ATP players, boys and girls 14 \& under) in four groups of shots, while the third aim was to establish if there were any differences in the timing of a split-step between groups of shots, players and the interaction of Player x Stroke Group.

\section{Material and Methods}

\section{Participants}

The Faculty of Sport's Human Ethics Committee approved the experimental design and protocol prior to the data collection. Matches $(\mathrm{n}=$ 15) were recorded at the national championship (Boys and Girls 14 \& under) and the international tournament (ATP players) on a Rebund Ace GS surface in an indoor tennis facility. All participants $(n=28)$ were considered highly trained and were ranked on the national (14 \& under players) or professional ranking list (male ATP players) (Table 1).

\section{Procedures}

During the tournaments, all matches were recorded with fixed SVHS video cameras (Ultrak CCD Colour KC 7501 CP) with a $25 \mathrm{~Hz}$ frequency of capturing input images. Each camera was fastened to the ceiling, allowing its wide-angled lens (Ultrak KL 28141s $2.8 \mathrm{~mm}$, Japan) to cover an entire half of the court. The video recordings were digitized using the Video DC30* video digitizer hardware (Miro, Germany) with a resolution of $384 \times 576$ at a data rate of $2 \mathrm{MBs}^{2}$, while processing was carried out at resolution of $384 \times 288$ pixels. The accuracy of the SAGIT system had been already tested in other studies (Filipcic et al., 2009b; Vuckovic et al., 2010).

The digital images were processed with the SAGIT/TENNIS tracking system using a computer vision method (Pers et al., 2002). The conversion into numerical data entailed the following steps: (1) recording tennis matches; (2) re-recording and compression of the recordings into digital format; (3) calibration of the recordings (time and space calibration); (4) data processing with the SAGIT/TENNIS tracking system (notation of players' movement, split-step, strokes, outcomes and game phases) and exporting into a database; and (5) processing the data with the statistical programme. 


\section{Analysis}

For the purpose of the study, the following data were collected: category, match, player, type of the stroke, frame and time at the opponent's impact point and player's split-step. The movement of tennis players was analyzed when faced with strokes from different opponents. For every stroke the split-step timing between the opponent's impact point when hitting the ball and the player's split-step (t-diff) was measured. If there was no split-step or it was not clearly visible, the situation was not included in the analysis.

Descriptive statistics (mean $\pm \mathrm{SD}$ ) are reported for the measured variables. A two-way analysis of variance (ANOVA) was used to determine the differences between groups of strokes, players and the interaction of the player and groups of strokes. A Tukey post-hoc test was employed to determine specific differences. To allow a better interpretation of the results, effect sizes (partial eta squared) were also calculated. The IBM SPSS Statistics version 21 was used for statistical calculations. The level of statistical significance was set at $p=0.05$.

\section{Results}

With 8,545 (Table 2) different strokes we measured split-step timing, which means the time between the impact point of the opponent's shot and the moment the player performed a split-step (Figure 1). To reflect various game situations, we divided shots into four groups of strokes: (1) the first and second serve; (2) return of the first and second serve; (3) baseline forehand and backhand; and (4) other shots. The frequency of occurrence of individual shots varied both among the shots, as well as among the different groups of shots and ranged from 1 execution (backhand smash) to 2,426 executed forehand topspin strokes. Average response time values for strokes which had a low frequency (less than 20) did not allow us to make generalizations in explaining the time coherence of a shot and the split-step, yet they clearly showed that there had been relatively few socalled special strokes. The dominant strokes were baseline strokes, where forehand was used more often than backhand, and the first serve was used 2.57 times more frequently than the second. When returning the serve, players performed more firstserve forehand returns and more second-serve backhand returns, while in the group of other shots the backhand slice was, as expected, the most frequent. There were no significant differences in the frequency of forehand and backhand volleys.

As expected, the mean response time was somewhat shorter after the first serve $(0.300 \mathrm{~s})$ than after the second one (0.334 s). Interestingly, in the return of the serve group, the lowest average time was measured after a second-serve forehand return $(0.293 \mathrm{~s})$, while values in other returns of the serve did not differ significantly. In the baseline group, the average values were somewhat lower after a topspin (0.315 s) and after a backhand topspin shot $(0.333 \mathrm{~s})$. The shortest response time was measured by both strokes that players performed at the net, namely a forehand (0.242 s) and a backhand volley (0.280 s), while between a forehand (0.369 s) and a backhand slice (0.339 s) there were no significant differences.

The total average value of individual groups of players differed in response time (Table 3), in girls it amounted to $0.297 \mathrm{~s}(\mathrm{SD}=0.106 \mathrm{~s})$, in ATP players to $0.306 \mathrm{~s}(\mathrm{SD}=0.062 \mathrm{~s})$ and in boys to $0.354 \mathrm{~s}(\mathrm{SD}=0.147 \mathrm{~s})$. The lowest average value in response time was measured in the ATP players by a game situation where a player received the first or the second serve $(0.281 \mathrm{~s})$. In this game situation, the girls achieved somewhat lower values $(0.311 \mathrm{~s})$ than the boys $(0.339 \mathrm{~s})$. The lowest values for the return of the serve (0.292 s), topspin forehand and backhand (0.289 s) at the baseline were measured in girls. In all four game situations, boys had the longest response time. For all three observed groups of players, the SD values were lower with the serve and return of the serve as opposed to both baseline shots.

Table 3 presents the split-step timing in the four stroke groups, as well as the total response time for all game situations. Players in all categories were divided according to their ranking on the ATP or national ranking lists. Among the ATP players, the best player was ranked on the $121^{\text {st }}$ place of the ATP list during the study. In 2014, this player was the winner of the US Open and his highest ranking was the $9^{\text {th }}$ place on the ATP ranking list. The second-best player in the measurement period was ranked on the $157^{\text {th }}$ place of the ATP ranking list. He achieved his highest ranking in 2013, when he was the $43^{\text {rd }}$. 
Table 1

Physical characteristics and ranking for the three players' groups. Values are expressed as mean ( $\pm S D$ ) and mean (range) for the players' ranking

\begin{tabular}{cccccc}
\hline Group & $\mathrm{N}$ & $\begin{array}{c}\text { Age } \\
(\text { years })\end{array}$ & $\begin{array}{c}\text { Body height } \\
(\mathrm{cm})\end{array}$ & $\begin{array}{c}\text { Body mass } \\
(\mathrm{kg})\end{array}$ & Ranking \\
\hline Boys 14 \& U & 11 & $13.8 \pm 0.7$ & $176 \pm 7.5$ & $67.6 \pm 11$ & $7(1-17)^{*}$ \\
\hline Girls 14 \& U & 10 & $14.1 \pm 0.5$ & $162.2 \pm 8.4$ & $52.1 \pm 4.4$ & $4,6(1-18)^{*}$ \\
\hline ATP players & 7 & $18.3 \pm 4.7$ & $181.4 \pm 9.5$ & $75 \pm 7.7$ & $380(121-1020)^{* *}$ \\
\hline \multicolumn{5}{c}{ "national ranking, ${ }^{* *}$ ATP ranking }
\end{tabular}

Table 2

Mean ( $\pm S D)$, stroke's number $(N)$ for response time at 1) serve, 2) return of serve,

3) base and 4) other strokes

\begin{tabular}{|c|c|c|c|c|}
\hline \multicolumn{2}{|c|}{ Stroke Group } & Mean & SD & $\mathrm{N}$ \\
\hline \multirow{3}{*}{1} & $1 \mathrm{~S}$ &, 300 & 0,104 & 1557 \\
\hline & $2 S$ & ,334 & 0,124 & 605 \\
\hline & Total & ,310 & 0,111 & 2162 \\
\hline \multirow{5}{*}{2} & 1SB & ,329 & 0,095 & 392 \\
\hline & $1 \mathrm{SF}$ & ,331 & 0,118 & 494 \\
\hline & $2 S B$ & ,321 & 0,081 & 290 \\
\hline & $2 S F$ & ,293 & 0,086 & 216 \\
\hline & Total & ,322 & 0,101 & 1392 \\
\hline \multirow{3}{*}{3} & BTS &, 333 & 0,136 & 1970 \\
\hline & FTS &, 315 & 0,130 & 2426 \\
\hline & Total & 323 & 0,133 & 4396 \\
\hline \multirow{11}{*}{4} & BDS & ,336 & 0,106 & 15 \\
\hline & BDV & 260 & 0,131 & 6 \\
\hline & BSL & 339 & 0,141 & 355 \\
\hline & BSM & , 160 & & 1 \\
\hline & BV & ,280 & 0,130 & 43 \\
\hline & FDS &, 284 & 0,117 & 11 \\
\hline & FDV & 314 & 0,104 & 19 \\
\hline & FSL & ,369 & 0,197 & 81 \\
\hline & FSM & ,282 & 0,094 & 18 \\
\hline & FV & 242 & 0,146 & 46 \\
\hline & Total & ,327 & 0,150 & 595 \\
\hline \multirow[t]{19}{*}{ Total } & BSM & , 160 & & 1 \\
\hline & FV & 242 & 0,146 & 46 \\
\hline & BDV & 260 & 0,131 & 6 \\
\hline & BV &, 280 & 0,130 & 43 \\
\hline & FSM &, 282 & 0,094 & 18 \\
\hline & FDS & .284 & 0,117 & 11 \\
\hline & $2 S F$ & ,293 & 0,086 & 216 \\
\hline & $1 \mathrm{~S}$ & 300 & 0,104 & 1557 \\
\hline & FDV & 314 & 0,104 & 19 \\
\hline & FTS & ,315 & 0,130 & 2426 \\
\hline & $2 S B$ & ,321 & 0,081 & 290 \\
\hline & 1SB & ,329 & 0,095 & 392 \\
\hline & 1SF & ,331 & 0,118 & 494 \\
\hline & BTS & 333 & 0,136 & 1970 \\
\hline & $2 S$ & ,334 & 0,124 & 605 \\
\hline & BDS & ,336 & 0,106 & 15 \\
\hline & BSL & ,339 & 0,141 & 355 \\
\hline & FSL & ,369 & 0,197 & 81 \\
\hline & Total & 320 & 0,124 & 8545 \\
\hline
\end{tabular}




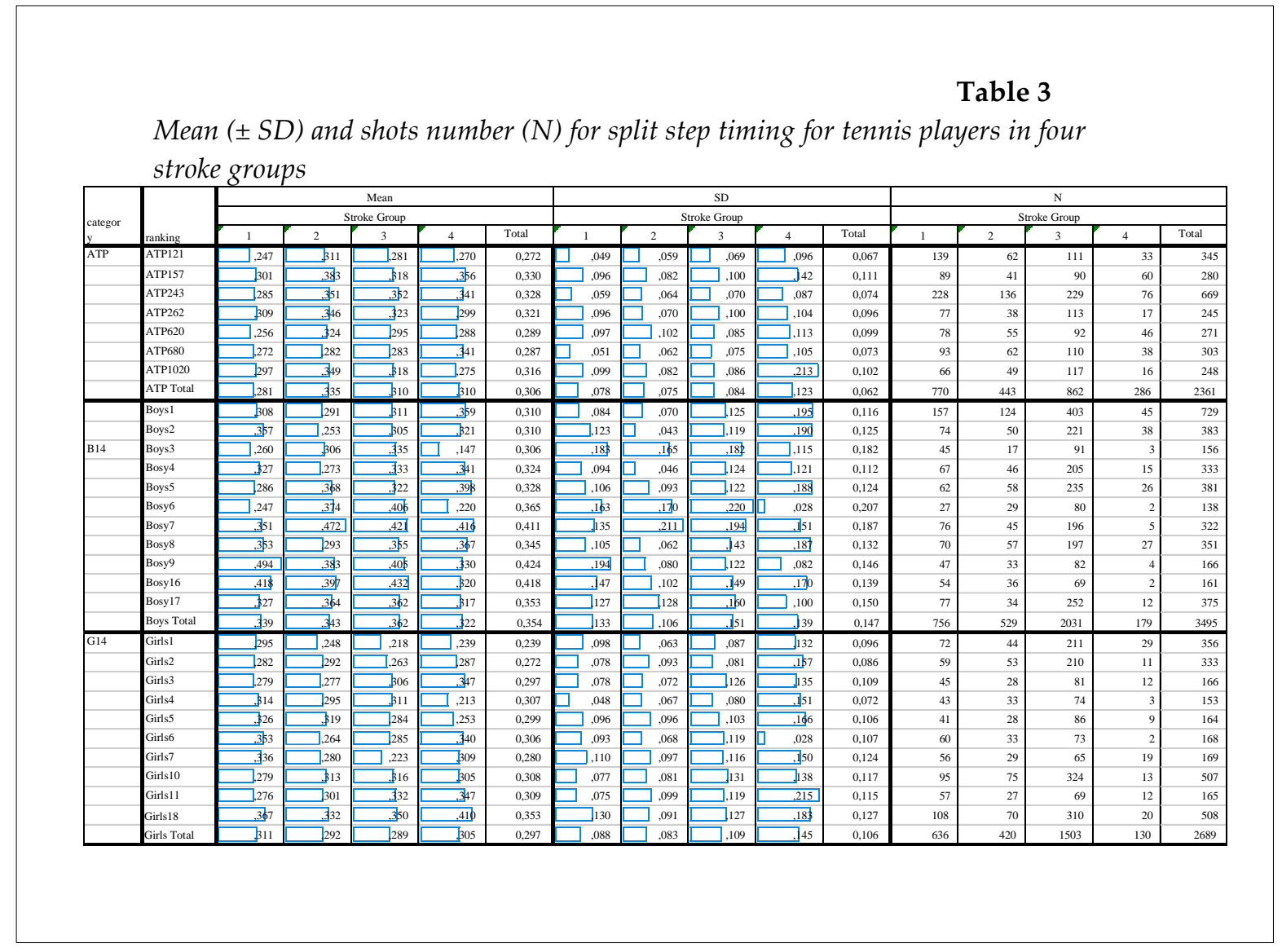

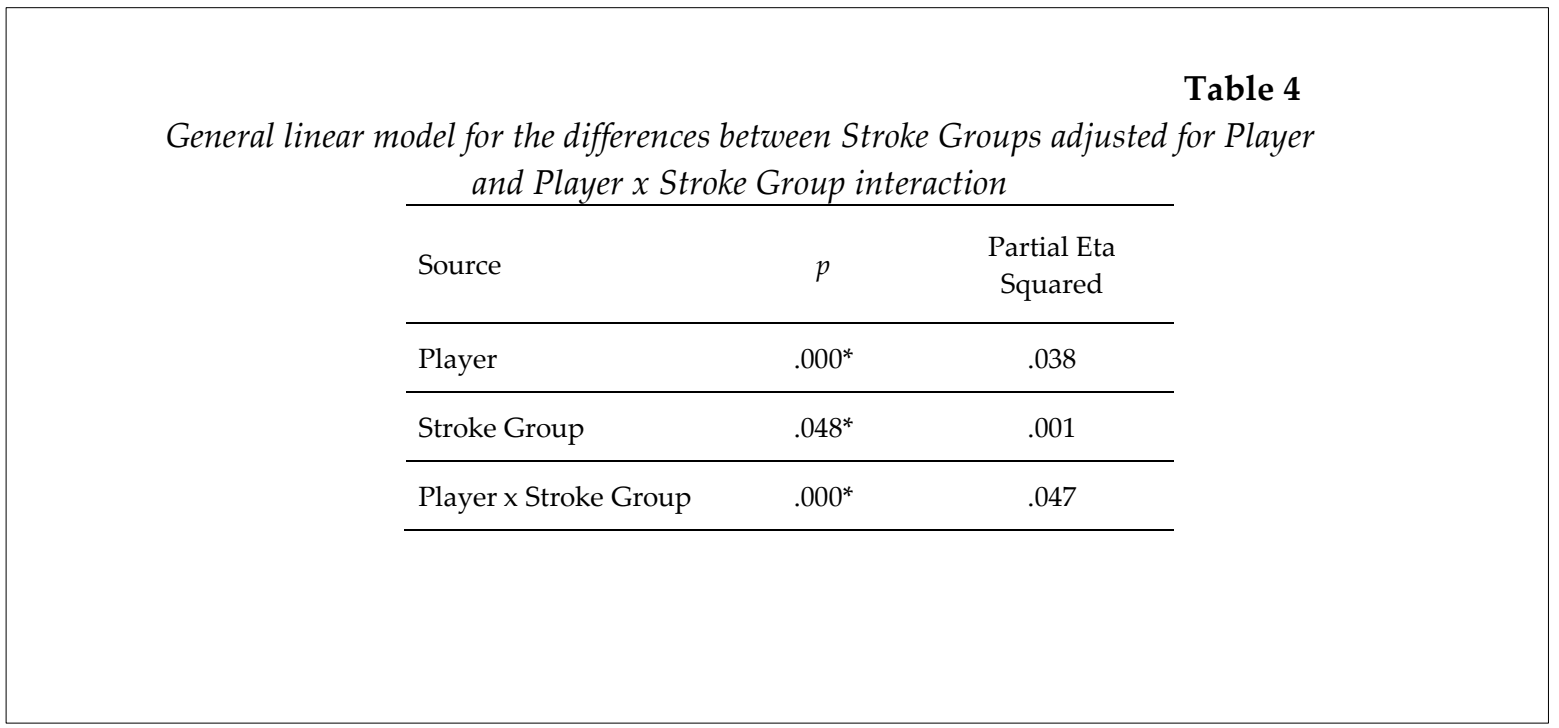

The first player on the national 14 \& under ranking list achieved low response time values. Her best professional ranking dated to 2011 when she was ranked on the $35^{\text {th }}$ place of the WTA ranking list.

The results obtained from the comparative analysis of the differences in split-step timing are presented in Table 4. Although all three model effects (Player, Stroke Group and their interaction) were significant, the effect of the stroke group was small (eta ${ }^{2}$ part. $\left.=0.001, p=0.048\right)$. According to the Tukey HSD test, the only significant pairs of stroke groups existed between group 1 (first and second serve) and all other groups. Differences 
between players were much higher (eta ${ }^{2}$ part. $=0.038$, $p<0.001)$. The interaction Player $\mathrm{x}$ Stroke Group was found to have the strongest effect (eta ${ }^{2}$ part. $=$ $0.047, p<0.001)$ in the model.

\section{Discussion}

The main goal of this study was to analyze the split-step timing in four different game situations as well as in three age and quality groups. Using the SAGIT system, we gathered timing data on the execution of all opponents' strokes and measured the players' response time per stroke.

We found the mean response time was $0.297 \mathrm{~s}$, which is longer than $0.183 \mathrm{~s}$ reported by Triolet et al. (2013) where, however, top 20 ATP players were included in the study and only selected strokes were considered. All the other studies analyzed the return of the serve. Thus, Nieminen et al. (2014) observed that the response time in a split-step situation was lower $(0.208 \pm$ $0.96 \mathrm{~s}$ ) than in a situation not involving a splitstep $(0.210-0.290 \mathrm{~s})$. Torres-Luque et al. (2011) in laboratory conditions measured an even lower average response time value at the return of the serve $(0.180 \pm 0.89 \mathrm{~s})$. They also defined this value as an optimal value for executing a split-step and a lateral step. Similarly, Le Runigo et al. (2005, 2010) reported that advanced tennis players had shorter visual-motor delays than novices in an interception task with deviated trajectories, with typical values below $0.200 \mathrm{~s}$. Carboch et al. (2014) found that the response time of the returner in realistic conditions was longer than when using a ball machine. Fernandez-Fernandez et al. (2008) in six returners measured the response time at between 0.161 and $0.237 \mathrm{~s}$. Djurovic et al. (2009) found non-significant differences between the forehand $(0.132 \pm 0.46 \mathrm{~s})$ and backhand return of the serve $(0.156 \pm 0.51 \mathrm{~s})$ and measured the longest response time in so-called reprogramming strokes $(0.297 \pm 0.121 \mathrm{~s})$.

We observed players' responses in different game situations (stroke groups). As expected, the response times varied significantly depending on the game situation and were on average lowest in the serve and then gradually increased from the return of the serve to the baseline game, reaching their highest values in specific game situations (drop shot, slice shot, volley, drive volley and smash). Players reacted faster in the first serve than in the second one and the response times in the return of the serve were lower after the return of the second serve. This indicates that players use lower speed of the incoming ball, play the return closer to the net, also more aggressively, which influences the lower response time. Also on the baseline we can assume that the speed of forehand topspins is higher, which influences the lower response time compared to after backhand topspins. Due to the more defensive execution of a backhand slice, the response time in this stroke is higher than in the backhand topspin. Shorter distance between the players influences the response time in both volley strokes which, on average, is lower than in baseline shots.

Triolet et al. (2013) found that professional tennis players in returns of the first and second serve and in volleys achieved response time values between 0.140 and $0.180 \mathrm{~s}$ after the opponent's impact point. In baseline rallies, the most frequent response time was on average higher and amounted in offensive and neutral situations to $0.160-0.480 \mathrm{~s}$. In our study, the baseline rally situation was best represented by forehand and backhand topspin shots. The average response times $(\mathrm{ATP}=0.310 \mathrm{~s}, \mathrm{~B}=0.362 \mathrm{~s}$, $G=0.289 \mathrm{~s}$ ) were within response times equal or superior to $0.160 \mathrm{~s}$ after the opponent's impact point, which was determined on a sample of professional tennis players.

Generally, the obtained results show that differences exist between players in detecting the opponent's movement, stroke and ball flight, which are reflected in different split-step timings. Apparently, each tennis player has his/her own time mechanism, which they also partly adapt to various game situations. This is especially evident in the split-step values in the first and second serve where, due to the speed of the ball, tennis players have considerably less time to detect, choose and execute their return shots.

The serve speed shortens the ball-flight time and influences the returner's response time. Carboch et al. (2014) on a sample of male tennis players measured that at a serve speed of $113 \mathrm{kph}$, the ball flight from the server to the returner lasted $1.1 \mathrm{~s}$ and at a speed of $130 \mathrm{kph}$ it lasted 0.96 s. Fernandez-Fernandez et al. (2008) reported higher average serve speeds, which in men were $162 \mathrm{kph}$, and in women $133 \mathrm{kph}$. Due to the 
higher serve speeds, the response times in the first and second serve (SG1) of the ATP players and boys 14 \& under were lower than in the baseline situation (SG3). The effect of a higher serve speed was not evident in girls 14 \& under who, on average, achieved lower response time values in the baseline situation (SG3) and in the return of the serve (SG2), which might lead to the assumption that the serve, especially the second one, is the weakest stroke in women's tennis (Antoun, 2007). However, this is not consistent with the latest findings of Reid et al. (2015) who in female players of the same age measured high serve speeds $(10.5$ years $=115 \mathrm{kph} ; 14.6$ years $=$ $151 \mathrm{kph} ; 21.5$ years $=158 \mathrm{kph}$ ).

Analyses of how different strokes affected player's response times showed small differences between stroke groups. The reported differences between different stroke groups were smaller than expected. Differences in response times among junior male, female and professional tennis players were significant and indicated individual split-step timing. To some degree, the differences were affected by different stroke groups. The differences between players can also be explained by the findings of Shim et al. (2005) who found that skilled tennis players showed individual differences in anticipation accuracy, and explained that players who were highly accurate in anticipation did not always have short response times. Variations in anticipation accuracy may be related to players' conscious strategies which are based on postural information (concentrating on various cues shoulder turn, player's position, racquet swing, etc.) or on tactical information (frequency of previously used tactical solutions).

Yet split-step timing values should by no means be considered only from the aspect of absolute values. Therefore, a lower response time value means better reaction ability, better anticipation, faster split-step execution, but the results also need to be interpreted from the aspect of the specificity of game situations. Triolet et al. (2013) concluded that player's response was influenced by their court position and the type of a situation: offensive (favorable), neutral or defensive (non-favorable). In defensive situations, players used two types of anticipation. In the first situation, they recognized the opponent's tactical intention before the impact point $(0.240-0.340 \mathrm{~s})$ and in the second they reacted immediately after the impact point $(0.100-0.200 \mathrm{~s})$. Otherwise, in situations with a response time exceeding $0.160 \mathrm{~s}$, professional players in $86.57 \%$ of cases chose the optimal tactical solution. Anticipation behaviors in professional tennis occur in between 6 and 13\% of shots played, meaning that in the vast majority of situations players have enough time to recognize all the important visual information in order to choose the optimal solution. Beside detecting and anticipating abilities, successful resolving of game situations is influenced by the ability to move quickly before, during (split-step) and after the stroke (Fernandez-Fernandez et al., 2008; Torres-Luque et al., 2011).

One limitation of our work may lie in capturing the situations for further analysis as only situations with an executed and clearly visible split-step were included in the study, and situations with the player's movements taking place before the opponent's impact point were not considered. Thus, we intentionally did not address the field of anticipation, which certainly has a significant influence on tennis players' splitstep timing and effectiveness, although, in a competitive situation anticipation is extremely difficult to be distinguished from other perceptive and psycho-motor skills. Furthermore, due to their low frequencies, the data on special shots do not allow generalization. Mainly in situations where we could expect specific behavior of players (net game, reaction to a drop shot), the differences between game situations were even more expressed, particularly in terms of tennis player's distance from the point of starting the movement to the stroke impact point and the player's movement speed before and after the split-step.

In conclusion, our data show that differences in time responses are influenced by time factors (perception, reaction abilities, anticipation, timing, speed, explosive power, rhythm, technical competencies, etc.) and spatial factors (court coverage, positioning, footwork, movement patterns, etc.), which in a competitive situation merge together to form a whole.

Our findings provide useful information for tennis coaches to create a wide range of opengame situations to practise and develop spatiotemporal constraints. In tennis training, coaches should take players' individual characteristics 
into account and identify game situations in which they are effective and those in which they are not. With player's age, training must include an increased number of game situations where tennis players are under time pressure (serve, net game and defensive game situations) and where the emphasis is also on the speed of movement, optimal split-step timing and a quick movement after the split-step.

\section{References}

Antoun R. Women's tennis tactics. Champaign, IL: Human Kinetics; 2007

Aviles C, Benguigui N, Beaudoin E, Godart F. Developing early perception and getting ready for action on the return of serve. CSSR, 2002; 28: 6-8

Barris S. Automatic tracking and the analysis of human movement. Int J Perform Anal Sport, 2008; 8: 102-113

Barros RM, Misuta MS, Menezes RP, Figueroa PJ, Moura FA, Cunha SA. Analysis of the distance covered by first division Brazilian soccer players obtained with an automatic tracking method. J Sports Sci Med, 2006; 6: 233-242

Bernardi M, De Vito G, Falvo ME, Marino S, Montellanco F. Cardiorespiratory adjustment in middle-level tennis players: are long-term cardiovascular adjustments possible? In Science and racket sports II, London: E \& FN Spon, pp 20-26. Less A, Maynard I, Hughes M, Reilly T, (Eds.); 1998

Brody H. Unforced errors and error reduction in tennis. Br J Sports Med, 2006; 40: 397-400

Carboch J, Süss V, Kocib T. Ball machine usage in tennis: movement initiation and swing timing while returning balls from a ball machine and from a real server. J Sports Sci Med, 2014; 13: 304-308

Carvalho J, Araújo D, Travassos B, Esteves P, Pessanha L, Pereira F, Davids K. Dynamics of players' relative positioning during baseline rallies in tennis. J Sports Sci, 2013; 31: 1596-1605

Cross R, Pollard G. Grand Slam men's singles tennis 1995-2009 Part 2: Points, games and sets. CSSR, 2011; 53: 3-6

Djurovic N, Lozovina V, Pavicic L. Evaluation of Tennis Match Data - New Acquisition Model. J Hum Kinet, 2009; 21: 15-21

Elliott B, Reid M, Crespo M. Biomechanics of advanced tennis. London: ITF, 73-92; 2003

Eubank C, Messenger N. Dynamic moves and stepping patterns typical to the game of squash. J Sports Sci, 2000; 18: 471-472

Fernandez-Fernandez J, Sanz-Rivas D, Fernandez-Garcia B, Mendez-Villanueva A. Match activity and physiological load during a clay-court tennis tournament in elite female players. J Sports Sci, 2008; 26: 1589-1595

Filipcic A, Pers J, Klevisar A. Comparison between young male and female tennis players in terms of time and movement characteristics, in Scientific approach in table tennis and tennis in Slovenia, Toronto: Sport Books Publisher, pp 143-148. Kondric M, Filipcic A (Eds.); 2009a

Filipcic T, Filipcic A, Pers J. Comparative analysis of time, playing and movement factors between two different quality groups of wheelchair tennis player, in Scientific approach in table tennis and tennis in Slovenia, Toronto: Sport Books Publisher, pp 195-199. Kondric M, Filipcic A (Eds.); 2009b

Hughes MD, Franks IM. Dynamic patterns of movement of squash players of different standards in winning and losing rallies. Ergonomics, 1994; 37: 23-29

Hurnik E, Unierzyski P, O'Donohue PO. Reliability of a computerised system for recording location on a tennis court. Int J Perform Anal Sport, 2008; 8: 138-144

James N, Bradley C. Disguising one's intentions: The availability of visual cues and situational probabilities when playing against an international level squash player, in Science and racket sports III, Abingdon, Oxon, UK: Routledge, pp 247-252. Lees A, Kahn JF, Maynard IW (Eds.); 2004

Katic R, Milat S, Zagorac N, Djurovic N. Impact of Game Elements on Tennis Match Outcome in Wimbledon and Roland Garros 2009. Coll Antropol, 2011; 35: 341-346 
Le Runigo C, Benguigui N, Bardy BG. Visuo-motor delay, information-movement coupling, and expertise in ball sports. J Sports Sci, 2010; 28: 327-337

Le Runigo C, Benguigui N, Bardy BG. Perception-action coupling and expertise in interceptive actions. Hum Mov Sci, 2005; 24: 429-445

Martínez-Gallego R, Guzmán JF, James N, Pers J, Ramón-Llin J, Vuckovic G. Movement Characteristics of Elite Tennis Players on Hard Courts with Respect to the Direction of Ground Strokes. J Sports Sci Med, 2013; 12: 275-281

Mauthner T, Koch C, Tilp M, Bischof H. Visual tracking of athletes in beach volleyball using a single camera. IJCSS, 2007; 6: 21-34

Nieminen MJ, Piirainen JM, Salmi JA, Linnamo V. Effects of neuromuscular function and split step on reaction speed in simulated tennis response. Eur J Sport Sci, 2014; 14: 318-326

O'Donoghue PG, Liddle D. A match analysis of elite tennis strategy for ladies' singles on clay and grass surfaces, in Science and Racket Sports II, London: E. and F. N. Spon, pp 241-246. Less A, Maynard I, Hughes M, Reilly T, (Eds.); 1998

O'Donoghue PG. Variability in men's tennis singles tennis strategy at the US Open, in Science and Racket Sports IV, Oxon: Routledge, pp 232-238. Lees A, Cabello D, Torres G, (Eds.); 2006

Pers J, Bon M, Kovacic S, Sibila M, Dezman B. Observation and analysis of large-scale human motion. Hum Mov Sci, 2002; 21: 296-311

Reid M, Giblin G, Whiteside D. A kinematic comparison of the overhand throw and tennis serve in tennis players: how similar are they really? J Sports Sci, 2015; 33: 713-723

Shim J, Carlton LG, Chow JW, Chae WS. The use of anticipatory visual cues by highly skilled tennis players. $J$ Mot Behav, 2005; 37: 164-175

Smekal G, Von Duvillard S, Rihacek C, Pokan R, Hofmann P, Baron R, Tschan H, Bachl N. A physiological profile of tennis match play. Med Sci Sports Exerc, 2001; 33: 999-1005

Terroba A, Kosters W, Varona J, Manresa-yee CS. Finding optimal strategies in tennis from video sequences. Int J Pattern Recogn, 2013; 27(6), Available at: http://www.medsci.cn/sci/show_paper.asp?id=a9154963958; accessed on 15.10.2015

Torres-Luque G, Cabello-Manrique D, Hernández-García R, Garatachea N. An analysis of competition in young tennis players. Eur J Sport Sci, 2011; 11: 39-43

Triolet C, Benguigui N, Le Runigo C, Williams AM. Quantifying the nature of anticipation in professional tennis. J Sports Sci, 2013; 31: 820-830

Verlinden M, Van Ruyskensvelde J, Van Gorp B, De Decker S, Goossens R, Clarijs JP. Effect of gender and tennis court surface properties upon strategy in elite singles, in Science and Racket Sports III, Abingdon, Oxon, UK: Routledge, pp 163-168. Lees A, Kahn JF, Maynard IW (Eds.); 2004

Vuckovic G, Dezman B, Erculj F, Kovacic S, Pers J. Comparative movement analysis of winning and losing players in men's elite squash. KinSi, 2003; 9: 74-84

Vuckovic G, Pers J, James N, Hughes M. Measurement error associated with the SAGIT/Squash computer tracking software. Eur J Sport Sci, 2010; 10: 129-140

Williams AM, Ford PR, Eccles DW, Ward P. Perceptual-cognitive expertise in sport and its acquisition: Implication for applied cognitive psychology. Appl Cogn Psychol, 2010; 25: 432-442

\title{
Corresponding author:
}

\author{
Ales Filipcic, PhD, Associated Professor \\ University of Ljubljana, Faculty of Sport, Gortanova 22, SI-1000 Ljubljana, Slovenia, \\ Phone: +386 41704 876, \\ Fax: +386 152077 40, \\ E-mail: ales.filipcic@fsp.uni-lj.si
}

